\title{
A copper-controlled RNA interference system for reversible silencing of target genes in Trichoderma reesei
}

\author{
Lei Wang, Fanglin Zheng, Weixin Zhang, Yaohua Zhong, Guanjun Chen, Xiangfeng Meng ${ }^{*}$ and Weifeng Liu
}

\begin{abstract}
Background: Trichoderma reesei is a primary lignocellulosic enzyme producer in industry. However, the mechanisms underlying cellulase synthesis as well as other physiological processes are insufficiently understood partly due to the sophisticated process for its genetic manipulation. Target gene knockdown by RNA interference (RNAi) is a powerful tool for genetic research and biotechnology in eukaryotes including filamentous fungi. Previously reported RNAi system in T. reesei was either uncontrollable or only applicable in certain nutrition state.
\end{abstract}

Results: In the present study, we incorporated the copper-responsive tcu1 promoter into an RNAi-mediated silencing system to develop a controllable RNAi-mediated silencing system in T. reesei. As the proof-of-concept, a prototrophic pyr4 gene, highly expressed cel7a and xyr 1 genes induced by Avicel and a fabl gene, whose knockout has proved to be intractable, were successfully knocked down in the absence of copper when the respective RNAi fragment was expressed. Importantly, the phenotype of RNAi strains was shown to be reversed easily to mimic the complementation for excluding any unwanted effects resulted from the random integration of the hpRNA cassette by adding copper in the media. Thus, this controllable RNAi-mediated silencing system can be turned on and turned off only depending on the absence and presence of copper ions in the media, respectively, and not on the nutritional states.

Conclusions: The copper-controlled RNA interference system represents an effective tool for reversible silencing of target genes in T. reesei. This reported strategy to conditionally knock down or turn off genes will contribute to our understanding of $T$. reesei gene functions, especially those that are difficult to be knocked out due to various reasons. In addition, this simple and cost-effective method holds great potential for the application in synthetic biology and genetic engineering of T. reesei.

Keywords: RNAi, Gene function, Trichoderma reesei, Copper-responsive promoter

\section{Background}

Bioconversion of the abundant renewable plant biomass consisting of lignocellulose holds great potential for the production of environmental friendly energy and chemicals [1]. Lignocellulose is primarily made of various interconnected biopolymers (e.g., cellulose, hemicellulose and lignin) and displays significant structural heterogeneity and complexity, which render them recalcitrant

*Correspondence: x.meng@sdu.edu.cn

State Key Laboratory of Microbial Technology, School of Life Science,

Shandong University, No.27 Shanda South Road, Jinan 250100, Shandong,

People's Republic of China to degradation [2]. The industrial use of plant biomass involves mechanical, chemical or physicochemical pretreatment steps followed by enzymatic hydrolysis to release the constituent monosaccharides for further fermentation to produce biofuels and biochemicals [3, 4]. As for the enzymatic hydrolysis step, multiple lignocellulosic enzymes, including cellulases, hemicellulases and polysaccharide lyases, are required to act synergistically to depolymerize cellulose and hemicellulose [5-7]. Preparation and use of these enzymes are therefore a major cost factor either due to the low catalytic performance 
and/or to the suboptimal composition of the enzyme cocktail under industrial conditions $[8,9]$.

The large amounts of lignocellulosic enzymes (e.g., cellulases and hemicellulases) secreted by the ascomycete Trichoderma reesei represent the prominent source of enzyme cocktails that are used in industry for biomass degradation [10-12]. Although industrial T. reesei strains have been reported to produce cellulases over $100 \mathrm{~g} / \mathrm{L}$ [13], the cost of enzyme production used in the saccharification step is still considered to be the major bottleneck of biomass conversion for the economical production of biofuels and biochemicals. Not surprisingly, T. reesei has been the subject of intensive investigation toward the improvement of its cellulases including increasing or reinforcing their existing activity and production to reduce the costs for biofuel production. The production of lignocellulosic enzymes by $T$. reesei involves many physiological processes including extracellular signal sensing [14, 15], intracellular signal transduction [16], transcriptional regulation of cellulase genes and protein synthesis [17, 18], and secretion [19]. Understanding the molecular mechanism behind these processes is crucial to further improve cellulase productivity of $T$. reesei.

Although the genomic sequence of $T$. reesei is now available, genes without an explicit function make up a large portion of the genome due to limited and intricate genetic manipulation approaches [20]. The gene knockout strategy by homologous recombination (HR) has been developed and widely used in $T$. reesei to study the function of particular genes [21, 22]. However, HR in $T$. reesei usually involves labor-intensive plasmid constructions for incorporating sufficiently long homologous arms on both sides of the target gene to ensure its occurrence at an inherent low efficiency [23]. As a result, large amounts of screening efforts are then needed to obtain the appropriate knockout strain. Although the low efficiency of HR has been partially solved by inactivating the genes (e.g., $t k u 70)$ in non-homologous end joining (NHEJ) pathway [23, 24], deleting these important DNA repair genes may exert unanticipated side effects. To solve this issue, Chum et al. [25] recently improved the efficiency of $\mathrm{HR}$ to certain extent by only transiently silencing tmus53 gene of NHEJ pathway. Nevertheless, the gene knockout strategy is improper to study a large proportion of important or essential genes, whose deletion proves to be intractable and results in severe growth defect or even inviability, making the phenotypic characterization impossible. On the other hand, tunable promoters controlled by external conditions have been shown to be useful for investigating the function of target genes in T. reesei $[26,27]$. Developing effective genetic manipulation systems by combining these induced or repressible promoters with conventional gene-targeting strategies is thus of prior importance to fully characterize such essential genes and genes with unknown functions.

The post-transcriptional gene silencing by small interfering RNA (siRNA)-mediated RNAi is triggered by double-stranded RNA and exists extensively in eukaryotes [28]. Soon after its discovery, RNAi becomes a powerful tool for functional genomic study due to its targeted nature, silencing of genes to the equivalent of null mutants and applicability to any transformable species of lower or higher eukaryotes [29, 30]. In many cases, RNAi is initiated by expressing a target gene fragment cloned as a tandem inverted repeat separated by a hairpin-forming intron sequence [29, 31]. The transcript creates a hairpin RNA (hpRNA) that then serves as a template for the RNAi machinery. There have been several studies describing the modulation of transcript abundance of specific genes in T. reesei using RNAi [31, 32]. Specifically, Qin et al. [31] have reported an inducible RNAi system with the cel7a promoter allowing induction of hpRNA expression in response to cellulose. Schmoll et al. [32] reported the knocking down of gan3, an adenylate cyclase-activating class III of G-alpha subunit, by expressing its antisense RNA driven by constitutive gpd 1 promoter in $T$. reesei. These systems, however, were either uncontrolled or relied on the transition of nutritional state which may result in many other side effects complicating the explanation for the observed phenotypes.

Here, we present a copper-controlled RNAi-mediated knockdown system in $T$. reesei by combining the previously identified copper-responsive $\mathrm{P}_{t c u 1}$ promoter with the routine RNAi vector for reversible silencing of different target genes. The usefulness of this system was demonstrated by the successful down-regulation of target genes in response to the absence of exogenous copper ions while maintaining their normal expression in the presence of copper. This copper-controlled RNAi system provides an alternative approach to characterize the functions of genes in $T$. reesei, especially those genes whose expression is under stringent regulation and thus extremely sensitive to any fluctuation in its expression level.

\section{Methods}

\section{Strains and culture conditions}

Escherichia coli DH5 $\alpha$ was used for plasmid construction and cultured in lysogeny broth with a rotary shaker (200 rpm) at $37{ }^{\circ} \mathrm{C}$. QM9414 (ATCC 26921) and a uridine auxotroph of $T$. reesei TU-6 (ATCC MYA-256) were used in this work as parental strains. The pyr4 gene-deleted strain of QM9414 (QM9414-_pyr4) was used as a control strain for pyr4 gene knocking down. All $T$. reesei strains were maintained on malt extract 
agar or liquid media supplemented with $10 \mathrm{mM}$ uridine when necessary. For the transcription and cellulase production analysis, spores were pre-grown in 1-L Erlenmeyer flasks on a rotary shaker $(200 \mathrm{rpm})$ at $30{ }^{\circ} \mathrm{C}$ with $250 \mathrm{~mL}$ Mandels-Andreotti (MA) media containing 1\% $(\mathrm{v} / \mathrm{v})$ glycerol as the carbon source for $48 \mathrm{~h}$ as previously described [18]. Mycelia were harvested by filtration and washed twice with media without a carbon source. Equal amounts of mycelia were then transferred to fresh media without peptone containing 1\% (w/v) Avicel and incubation was continued for the indicated time periods. Copper was present or absent perpetually in the media from pre-culture to induction. For vegetative growth on agar plates, equal amounts of growing mycelia or spores were inoculated on minimal media agar plates containing $1 \%$ $(\mathrm{w} / \mathrm{v})$ glucose at $30^{\circ} \mathrm{C}$ for several days. The Avicel doublelayer plates where the minimal media agar without carbon source was covered by $1 \%(\mathrm{w} / \mathrm{v})$ Avicel were used for investigating cellulase production.

\section{Construction of plasmids and strains}

The 744-bp HindIII-EcoRV fragment containing $\mathrm{P}_{t c u 1}$ promoter, 1041-bp Spe1-Sal1 fragment containing $\mathrm{T}_{\text {cel6a }}$ terminator and 179-bp EcoRV-Spe1 fragment containing $\mathrm{I}_{c e l 5 a}$ intron were amplified by PCR from the genomic DNA of T. reesei QM9414 and then inserted into pMD19T- $h p h$ vector containing the hygromycin-resistance gene by an orderly manner (Fig. 1a) for the construction of pKD-hph vector. Restriction sites EcoRV-Kpn1 and Spe1-Not1 are used to insert forward and reverse complemented RNAi fragment, respectively. The 788-bp EcoRV-Kpn1 fragment containing xyr1 cDNA sequence and reverse complemented Spe1-Not 1 fragment were amplified by PCR from the total cDNA of Avicel-inducing T. reesei QM9414 and then were ligated into pKD-hph (Fig. 1b), generating pKD-hph-xyr1. The 905-bp cel7a cDNA sequence, 736-bp pyr4 cDNA sequences and 714-bp fab1 cDNA sequences, and their reverse complemented fragments, were inserted into pKD- $h p h$ in the same way as pKD-hph-xyr1, resulting in pKD-hph-cel7a, pKD-hph-pyr4 and pKD-hphfab1, respectively. To construct $\mathrm{P}_{t c u 1}-x y r 1^{\mathrm{KD}}$ strain, the linearized pKD-hph-xyr1 vector with $S s p 1$ was used to transform $T$. reesei strain. Transformation of $T$. reesei was carried out essentially as described by Penttila [21]. Transformants were selected on minimal media containing $120 \mu \mathrm{g} / \mathrm{mL}$ hygromycin. Genomic PCR was used to verify correct integration events using a $2 \times \mathrm{T} 5$ Super PCR Mix (TSE005, Beijing Tsingke Biotech Co., Ltd) as described in Additional file 1. Primers for plasmids construction and genomic PCR are also provided in Additional file 1 . The knocking down of target genes was

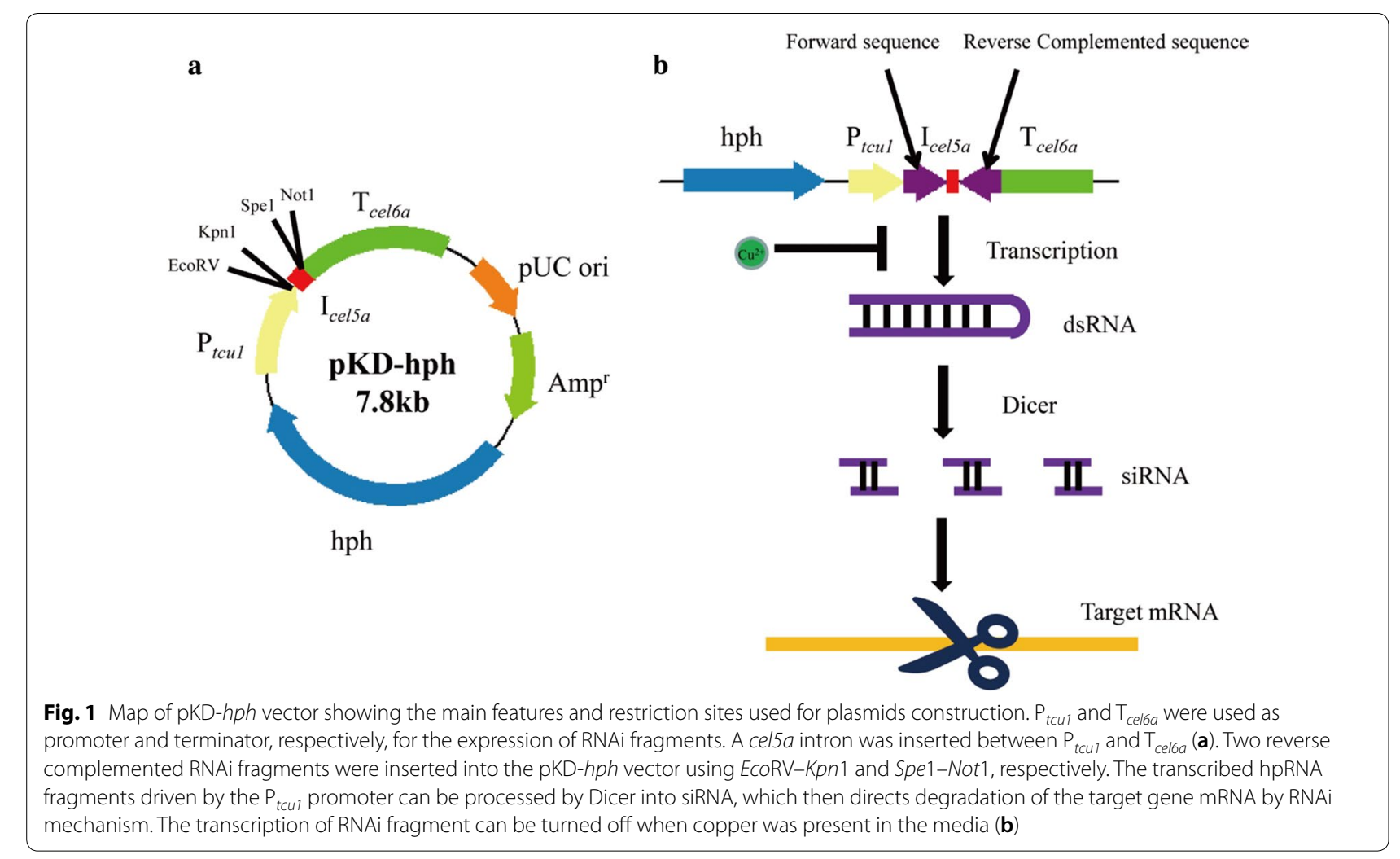


confirmed by comparing their mRNAs level in the media supplied with and without $\mathrm{CuSO}_{4}$.

\section{Enzyme activity and protein analysis}

The activities of cellobiohydrolases (pNPCase) and $\beta$-glucosidases (pNPGase) were determined by measuring the amount of released $p$-nitrophenol using $p$-nitrophenyl- $\beta$-D-cellobioside (pNPC; Sigma, St. Louis, United States) and $p$-nitrophenyl- $\beta$-D-glucopyranoside (pNPG; Sigma) as substrates, respectively. The pNPC and pNPG activity assays were performed in $200 \mu \mathrm{L}$ reaction mixtures containing $50 \mu \mathrm{L}$ of culture supernatant and $50 \mu \mathrm{L}$ of the respective substrate plus $100 \mu \mathrm{L}$ of $50 \mathrm{mM}$ sodium acetate buffer $(\mathrm{pH} 4.8)$ and then incubated at $45{ }^{\circ} \mathrm{C}$ for $30 \mathrm{~min}$. One unit (U) of pNPCase or pNPGase activity was defined as the conversion of $1 \mu \mathrm{mol}$ of substrate per minute under the test conditions as described previously [33]. The endo-glucanases and the filter paper activities (FPA) were determined by measuring the released reducing sugar with carboxymethylcellulose sodium salt (CMC; Sigma) and filter paper as substrates, respectively. Determination of the $\mathrm{CMC}$ hydrolytic activities was carried out at $50^{\circ} \mathrm{C}$ in a $100 \mu \mathrm{L}$ reaction mixture containing $50 \mu \mathrm{L}$ of appropriately diluted culture supernatant and $50 \mu \mathrm{L}$ of $0.5 \%(\mathrm{w} / \mathrm{v}) \mathrm{CMC}$ sodium in $50 \mathrm{mM}$ sodium acetate buffer ( $\mathrm{pH} 4.8$ ). The FPA assay was performed at $50{ }^{\circ} \mathrm{C}$ in a $200 \mu \mathrm{L}$ reaction mixture including $50 \mu \mathrm{L}$ of appropriately diluted culture supernatant and $150 \mu \mathrm{L} 50 \mathrm{mM}$ sodium acetate buffer ( $\mathrm{pH} 4.8$ ) with Whatman No. 1 filter paper as substrates. One unit (U) of CMCase or FPA was defined as the release of $1 \mu \mathrm{mol}$ reducing sugar per minute under the test conditions [33]. Total secreted and intracellular proteins were determined using the Bradford protein assay with bovine serum albumin (BSA) as a standard. SDS-PAGE and Western blotting were performed according to the standard protocols and Cel7a was immunoblotted using a polyclonal antibody raised against amino acids $426-446$ of the protein as previously described [34].

\section{Quantitative RT-PCR (qRT-PCR)}

Total RNAs were extracted using the Trizol reagent (Invitrogen, Grand Island NY, United States) and purified using the TURBO DNA-free kit (Ambion, Austin TX, United States) to eliminate the genomic DNA contamination according to the manufacturer's instructions. Reverse transcription was performed using the PrimeScript RT reagent Kit (Takara, Japan) according to the instructions. Quantitative PCR was performed using SYBR green supermix (TaKaRa, Japan) on a BioRad myIQ2 thermocycler (Bio-Rad, California, United States). Data were analyzed using the relative quantitation/comparative threshold cycle $(\Delta \Delta \mathrm{CT})$ method and were normalized to the endogenous gene actin. Primers for qRT-PCR are provided in Additional file 1. Three biological replicates were performed for each analysis and the results and errors are the mean and standard deviation (SD), respectively. Statistical analysis was performed using the Student's $t$ test analysis.

\section{Designed culture procedure for investigating the fab1 gene function in $T$. reesei using copper-responsive RNAi system}

In order to exclude the indirect effects of growth difference brought from pre-culture, we took $\mathrm{P}_{t c u 1}-f a b 1^{\mathrm{KD}}$ strain as an example to redesign a culture strategy to characterize the function of $f a b 1$ in cellulase production in T. reesei. First, copper was added into MA media containing $1 \%$ glycerol as a sole carbon source in the first pre-culture for $36 \mathrm{~h}$. Harvested mycelia were washed five times with media without a carbon source and then transferred to fresh MA media supplied without copper. After $12 \mathrm{~h}$ culturing, mycelia were harvested again and washed two times with media without a carbon source. Finally, mycelia were transferred to induced media containing 1\% Avicel supplied without copper. As a control, $\mathrm{P}_{t c u 1}-f a b 1^{\mathrm{KD}}$ strain was also culture in parallel with copper perpetually in the media to repress the expression of $f a b 1$ gene RNAi fragments. The mRNA level of $t c u 1$ and $f a b 1$ were analyzed in the ending of first (Fig. 6b, c: sampling time S1) and second (Fig. 6b, c: sampling time S2) pre-culture by qRT-PCR. Besides, their mRNA abundance also was analyzed after mycelia grow under induced condition at $6 \mathrm{~h}$ (Fig. 6b, c: sampling time S3) and $12 \mathrm{~h}$ (Fig. 6b, c: sampling time S4), respectively. Cellulase production was assessed at 12, 24, 36, 4860 and $72 \mathrm{~h}$ after the mycelia were transferred to the Avicel inducing media by measuring the FPA activity and SDSPAGE analysis.

\section{Results \\ Design of copper-responsive RNAi-mediated silencing system}

The controllability of the $\mathrm{P}_{t c u 1}$ promoter was incorporated into an RNAi-mediated silencing system in $T$. reesei. As shown in Fig. 1, gene-specific sequence was cloned as a tandem inverted repeat arranged on both sides of an intron from the cel5a gene to build synthetic hpRNA fragments, which was then inserted downstream of the $\mathrm{P}_{t c u 1}$ promoter. The transcription of hpRNA fragments for target genes will result in the formation of double-stranded RNA that is recognized by Dicer and then produces siRNA to induce degradation of target mRNAs. In our present strategy, hpRNA fragments driven by $\mathrm{P}_{t c u 1}$ are thus expected to down-regulate the transcript levels of the target gene when no copper ions were included in 
the media. Silencing can be reversed by adding back copper ions to mimic gene complementation.

\section{Copper-responsive RNAi-mediated silencing of the prototrophic gene pyr4}

The pyr4 gene encodes an orotidine $5^{\prime}$-phosphate decarboxylase which is involved in the uridine biosynthesis. Knockout of endogenous gene pyr4 in T. reesei showed that cells cannot survive unless uridine is present in the media [35]. Pyr4 is thus widely used as a screening marker in the genetic manipulation of T. reesei [22]. In order to test whether the RNAi-mediated silencing system can efficiently work in response to exogenous copper, the pyr4-specific hpRNA fragments were inserted downstream of the $\mathrm{P}_{t c u 1}$ promoter in the $\mathrm{pKD}$ - $h p h$ vector, generating the $\mathrm{pKD}-h p h-p y r 4$ plasmid. Transformants $\left(\mathrm{P}_{t c u 1}-\right.$ pyr $\left.4^{\mathrm{KD}}\right)$ were first selected on minimal media for resistance to hygromycin. Hyphal growth of selected $\mathrm{P}_{\text {tcu }}-$ pyr $^{\mathrm{KD}}$ strains on minimal media agar plates with glucose as the sole carbon source was investigated. As showed in Fig. $2 \mathrm{a}, \mathrm{P}_{\text {tcul }}-$ pyr $4^{\mathrm{KD}}$ spores barely germinated in glucose minimal media agar plate without addition of copper, which is also observed with the control strain QM9414-Dpyr4, demonstrating that the pyr4 gene was knocked down by the RNAi-mediated silencing system. Adding $20 \mu \mathrm{M}$ copper (Fig. 2b) or $10 \mathrm{mM}$ uridine (Fig. 2c) in the media rescued the growth, equivalent to the restored growth of QM9414- - pyr4 on media only with $10 \mathrm{mM}$ uridine (Fig. 2c). Under the above-tested conditions, the growth of QM9414affected by copper. These results revealed that the $\mathrm{P}_{t c u 1}$ promoter controlled the transcription of pry4 RNAi fragment to knock down of pyr4 gene in response to the external copper.

\section{Copper-controlled RNAi-mediated knockdown of cellulose-induced genes}

To further test the effectiveness of the developed system, we selected two cellulose-induced genes for our proof-of-concept study. XYR1 is a critical activator for the transcription of cellulase and hemicellulase genes in $T$. reesei, deletion of which resulted in the abolishment of the induced production of nearly all (hemi)cellulases [36, 37]. The transcription of xyr1 itself has been also shown to be induced by cellulosic substrates such as Avicel and by lactose in T. reesei [38]. CEL7A is the major cellulase component produced by $T$. reesei and is shown to be tightly regulated by XYR $1[39,40]$. T. reesei QM9414 was first transformed with the pKD-hph-xyr1 and the cellulolytic activity of selected RNAi transformant was determined. As shown in Fig. 3a, the FPA was almost abolished in the $\mathrm{P}_{t c u 1}-x y r 1^{\mathrm{KD}}$ strain just as that of the $\Delta x y r 1$ strain, but remained at a similar level to that of QM9414 strain when $20 \mu \mathrm{M}$ copper was present in the Avicel inducing media. In contrast to the $\mathrm{P}_{t c u 1}-x y r 1^{\mathrm{KD}}$ strain, only a slight increase of the extracellular FPA was observed with copper compared to that without copper for QM9414. The extracellular protein concentration

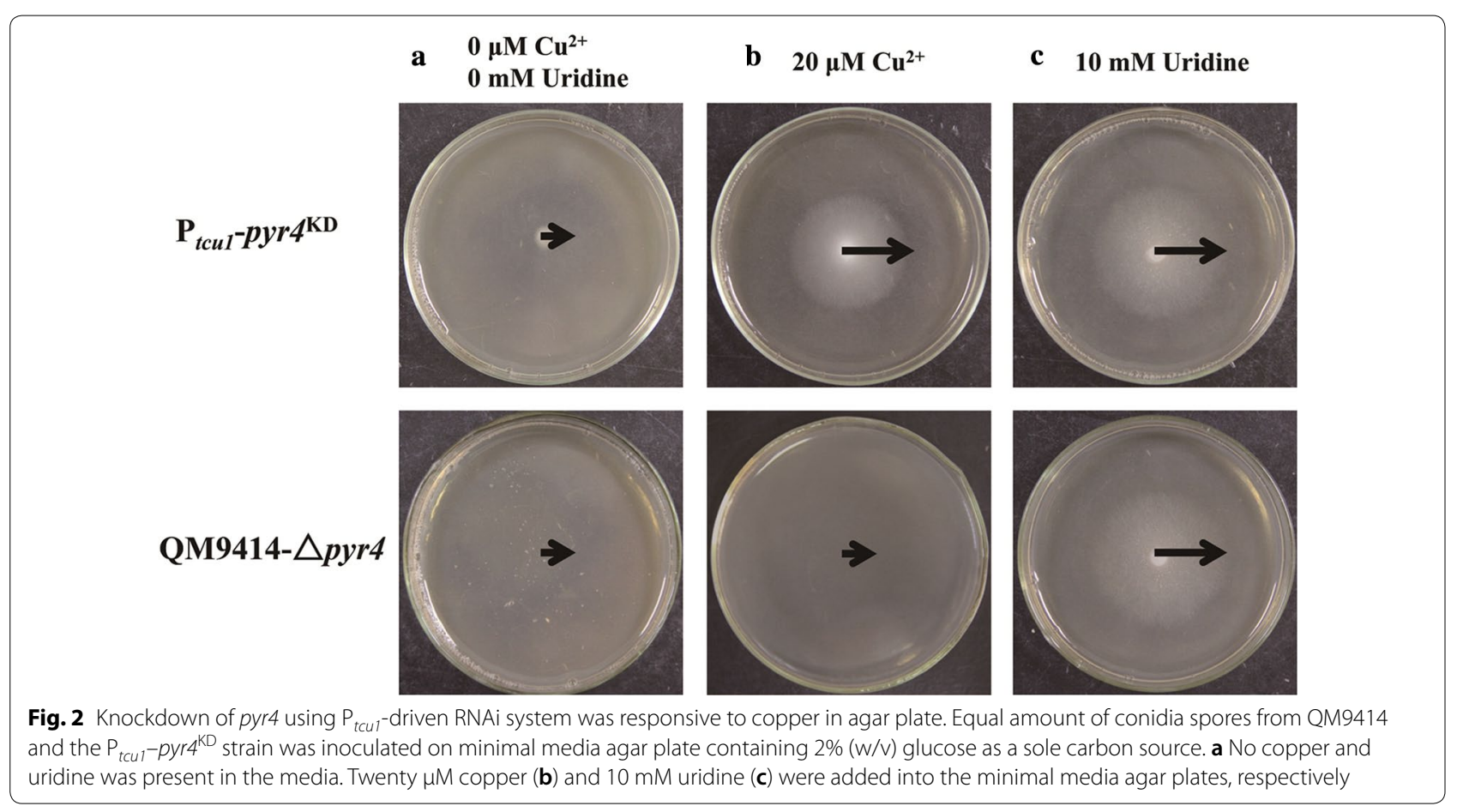


of the $\mathrm{P}_{t c u 1}-x y r 1^{\mathrm{KD}}$ strain was also found to be dramatically reduced in the absence of copper, but maintained a similar level to that of the parental strain QM9414 in the presence of copper. SDS-PAGE analysis verified that the overall secreted proteins of the $\mathrm{P}_{t c u 1}-x y r 1^{\mathrm{KD}}$ strain under inducing conditions were severely reduced without copper, whereas no significant difference was observed with QM9414 when induced in the presence or absence of copper (Fig. 3c). To test whether the reduced FPA and extracellular protein were the results of down-regulation of xyr1 mRNAs, we determined the transcript level of $x y r 1$ and that of cellulase genes cel7a and $c e l 7 b$ by quantitative qRT-PCR. The abundance of $x y r 1$ mRNAs in the $\mathrm{P}_{t c u 1}-x y r 1^{\mathrm{KD}}$ strain was obviously reduced compared to that of QM9414 under Avicel inducing conditions without copper (Fig. 3f). In contrast, xyr 1 mRNAs in the $\mathrm{P}_{t c u 1}-x y r 1^{\mathrm{KD}}$ strain were restored to a similar level to that QM9414 when copper ions were added to the Avicel inducing media (Fig. 3i). Similar to the case of $\Delta x y r 1$, the transcription of $c e l 7 a$ and $c e l 7 b$ in the $\mathrm{P}_{t c u 1}-x y r 1^{\mathrm{KD}}$ strain was severely reduced upon induction in the absence of copper (Fig. 3d, e). Adding $20 \mu \mathrm{M}$ copper ions into the inducing media restored their transcription to levels comparable to those of the QM9414 strain (Fig. 3g, h).

Copper-controlled RNAi-mediated down-regulation of the highly transcribed cel7a was also tested. As shown in Fig. 4a, the parental strain QM9414 showed apparent hydrolytic halo on Avicel both with and without $20 \mu \mathrm{M}$ copper. Similar hydrolytic halo was observed for the RNAi strain when $20 \mu \mathrm{M}$ copper was included in the media. However, the $\mathrm{P}_{t c u 1}-$ cel $7 a^{\mathrm{KD}}$ strain only displayed a very limited hydrolysis of Avicel when no copper was added. SDS-PAGE and Western blot analysis demonstrated that CEL7A was not detected in the extracellular supernatant of the $\mathrm{P}_{t c u 1}-c e l 7 a^{\mathrm{KD}}$ strain in the absence of copper upon induction (Fig. 4b). Together, these results demonstrated that highly expressed xyr1 and cel7a induced by Avicel could be successfully knocked down by the $\mathrm{P}_{t c u 1}$-driven RNAi approach in a controllable manner wherein the expression of XYR1 and CEL7A became responsive to the external copper levels in the media.

\section{Copper-controlled silencing of fab1 encoding phosphatidylinositol 3,5-bisphosphate kinase compromises cellulase production}

Trichoderma reesei fab1 gene ( $\left.\operatorname{Tr}_{-} 78274\right)$ is annotated to encode phosphatidylinositol-3-phosphate 5-kinase homolog catalyzing the phosphorylation of phosphatidylinositol 3-phosphate (PtdIns(3)P) to yield phosphatidylinositol 3,5-bisphosphate $\left(\operatorname{Ptd} \operatorname{Ins}(3,5) \mathrm{P}_{2}\right)$ [41, 42]. Deletion of fab1 in Saccharomyces cerevisiae has been reported to result in severe growth defect and exhibited enlarged vacuole probably due to the defect in vacuolar membrane recycling/turnover [43, 44]. Moreover, $\operatorname{PtdIns}(3,5) \mathrm{P}_{2}$ has been reported to play a role in recruiting SAGA complex to the gal1 gene promoter to activate the gene transcription in S. cerevisiae [45]. We thus made multiple attempts to delete the $f a b 1$ homolog in T. reesei by HR for investigating its function on cellulase production but without success. This failure implied that $f a b 1$ may be essential for viability because we did not obtain strains with a complete removal of the endogenous $f a b 1$ gene (data not shown). Thus, we chose to conditionally knock down the expression of fab1 in T. reesei using the copper-responsive RNAi silencing strategy. As shown in Fig. 5a, the $\mathrm{P}_{t c u 1}-f a b 1^{\mathrm{KD}}$ strain showed an approximately $80 \%$ decline in $f a b 1$ transcript abundance in the absence of copper upon Avicel induction, whereas no significant effect was observed when the RNAi strain was cultured with $20 \mu \mathrm{M}$ copper. In addition, RNAi-mediated downregulation of the $f a b 1$ gene did not result in a visible phenotype regarding mycelial growth and sporulation (Fig. 5e, f). To further evaluate the function of $f a b 1$ in cellulase induction, pNPCase, pNPGase and CMCase activities of the parental strain and the $\mathrm{P}_{t c u 1}-f a b 1^{\mathrm{KD}}$ strain cultured on 1\% (w/v) Avicel with or without copper were determined (Fig. 5b-d). The results revealed that the parental strain showed similar pNPCase, pNPGase and CMCase activity upon induction regardless of the presence or absence of copper, whereas the $\mathrm{P}_{t c u 1}-f a b 1^{\mathrm{KD}}$ strain displayed significantly decreased hydrolytic activities in the absence of copper. Supplementing copper to the inducing media restored the production of the above cellulases in the RNAi strain. Interestingly, the observed defect in cellulase induction in the $\mathrm{P}_{t c u 1}-f a b 1^{\mathrm{KD}}$ strain did

(See figure on next page.)

Fig. 3 The effect of $x y r 1$ knockdown by copper-responsive RNAi-mediated silencing system. The extracellular FPA (a) and protein concentration (b) of the parental and $\mathrm{P}_{\text {tcul }}-x y r 7^{\mathrm{KD}}$ strains cultured on 1\% (w/v) Avicel supplied with or without CuSO ${ }_{4}$ were determined as described in "Methods" section. SDS-PAGE analysis of the total extracellular protein accumulation (c) of the $\mathrm{P}_{\mathrm{tcul}}-x y r r^{\mathrm{KD}}$ and the parental strains cultured on $1 \%$ ( $\mathrm{W} / \mathrm{v}$ ) Avicel supplied with or without $\mathrm{CuSO}_{4}$, respectively, at the indicated time points. qRT-PCR analysis of intracellular mRNA levels of the endogenous cel7a, cel7b, and $x y r 1$ in parental and $\mathrm{P}_{\mathrm{tcu}}-x y r 7^{\mathrm{KD}}$ strains was performed at the indicated time points with $(\mathbf{g}-\mathbf{i})$ or without (d-f) CuSO $\mathrm{C}_{4}$. A significant difference ( $t$ test $P<0.05$ ) was detected for the expression of cel $7 a$, cel $7 b$, and $x y r 1$ in parental and $P_{\text {tcul }}-x y r 7^{\mathrm{KD}}$ strains. Error bars are SD from three biological replicates 

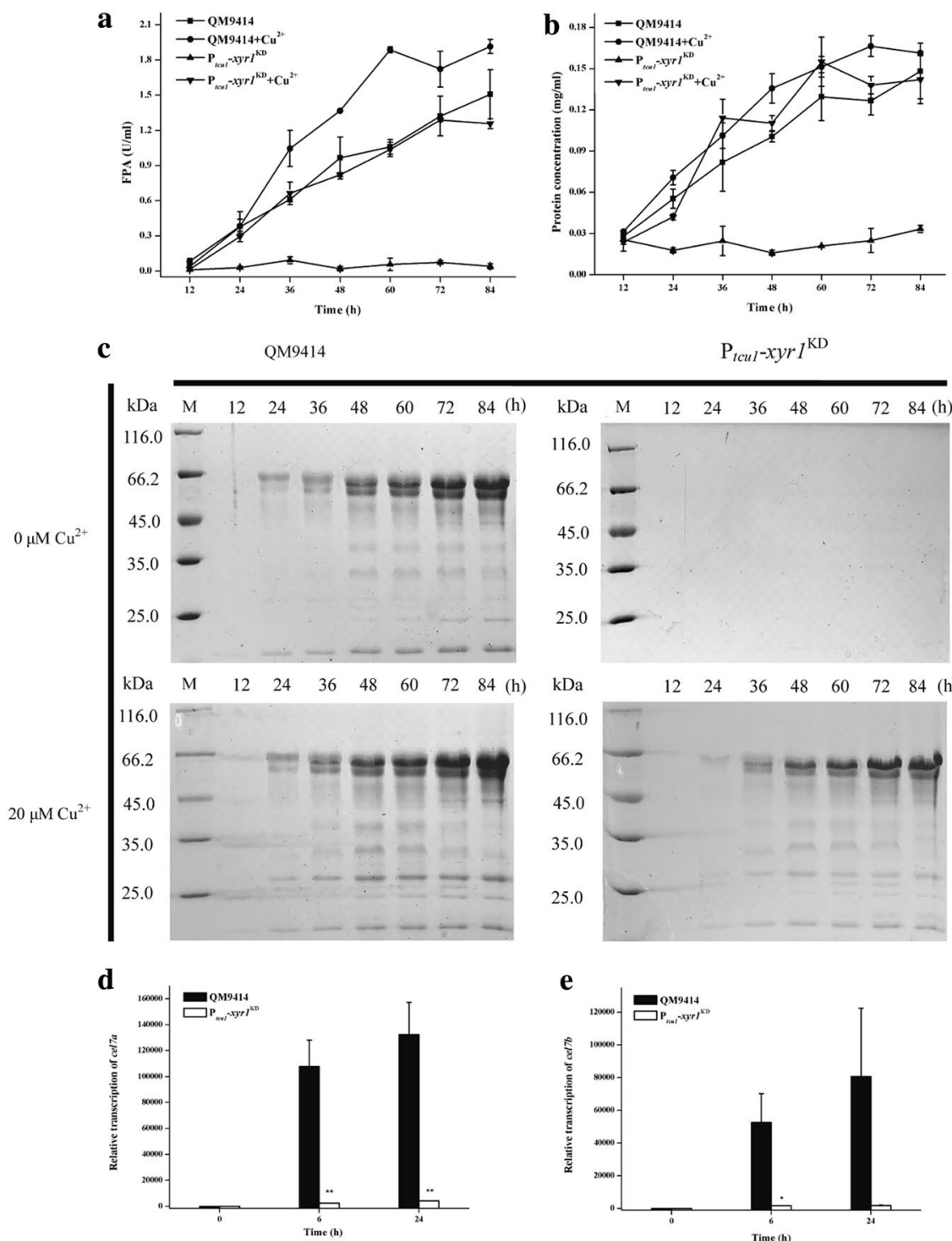

$\mathrm{P}_{\text {tcul }}-x y r 1^{\mathrm{KD}}$

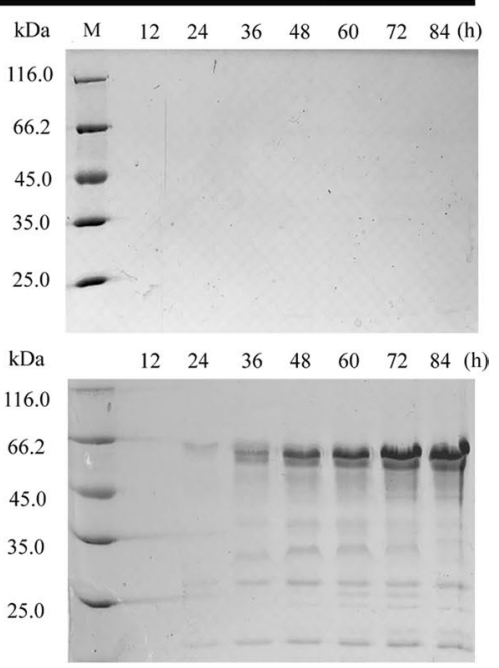

f
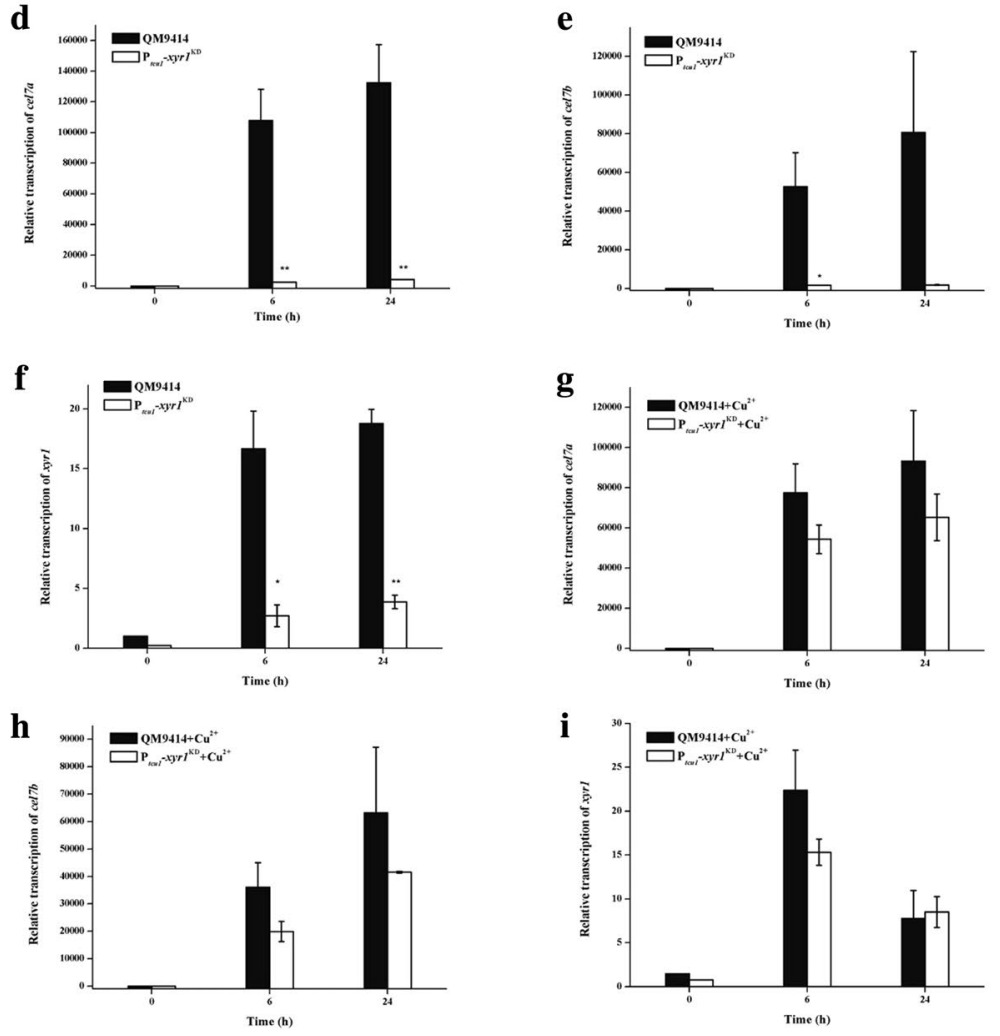


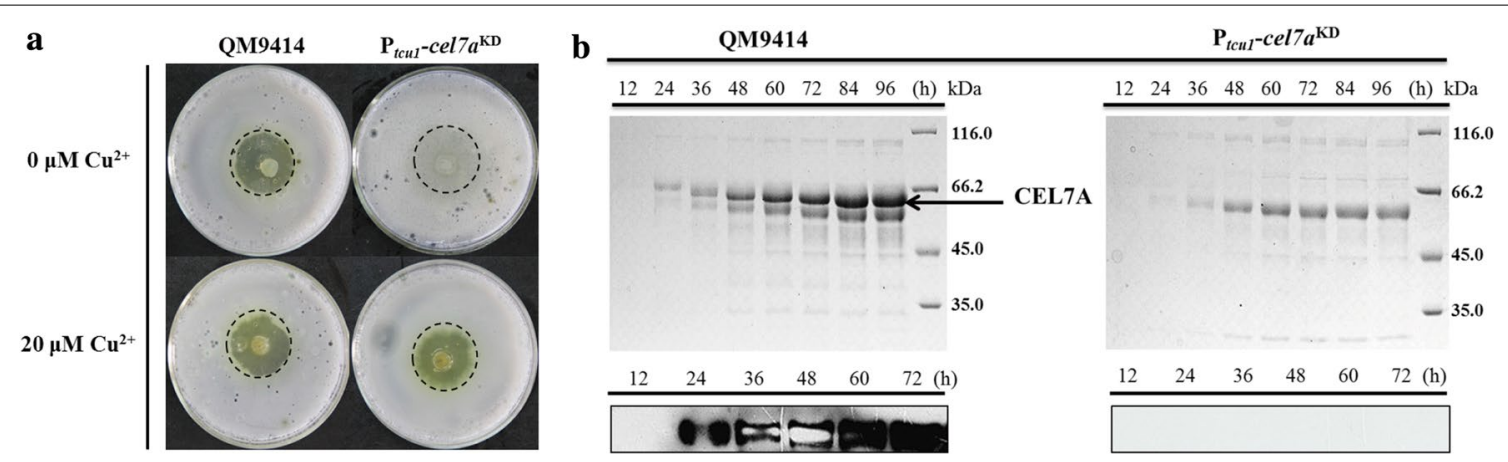

Fig. 4 Knockdown of cel7a by the copper-responsive RNAi-mediated silencing system. Mycelial growth on double-layer agar plate containing 1\% $(\mathrm{W} / \mathrm{v})$ Avicel supplied with or without copper (a). The parental and the $\mathrm{P}_{\mathrm{tcu}}-x y \mathrm{r}^{\mathrm{KD}}$ strains were cultured in Avicel-induced media without copper. The total extracellular proteins from both strains were analyzed by SDS-PAGE and Western blot at the indicated time points (b)

not seem to occur at the transcription level since there was no significant reduction in transcript abundance of the $c e l 7 a$ and $c e l 7 b$ genes when cultured without copper (Additional file 1).

In order to exclude any indirect effect by growth difference originating from the pre-culture on phenotype characterization, we also took the $\mathrm{P}_{t c u 1}-f a b 1^{\mathrm{KD}}$ strain as an example to compare different culture strategies to verify the role of $f a b 1$ in cellulase production in T. reesei. As shown in Fig. 6a, the $\mathrm{P}_{t c u 1}-f a b 1^{\mathrm{KD}}$ strain was pre-cultured for $36 \mathrm{~h}$ on glycerol with $20 \mu \mathrm{M}$ copper. The transcription of the $f a b 1 \mathrm{hpRNA}$ fragment was repressed during this process with the $\mathrm{P}_{t c u 1}-f a b 1^{\mathrm{KD}}$ strain displaying the same growth as the parental strain. After extensive washing, the pre-cultured mycelia were inoculated in fresh glycerol media with or without copper and incubated for $12 \mathrm{~h}$, allowing the siRNAs targeting the $f a b 1 \mathrm{mRNA}$ to be accumulated during this period only in the absence of copper. Mycelia after this stage of growth were finally transferred into Avicel media with and without copper, respectively. The transcript abundance of $t c u 1$ and fab1, filter paper activity, and extracellular protein concentrations of culture samples taken at specific time points (Fig. 6a: sampling time S1, S2, S3, S4) during the whole process were determined. As expected, the tcul promoter was immediately switched on when the pre-cultured mycelia were transferred to glycerol media without copper and maintained a relatively high-level expression after being transferred to the corresponding inducing conditions (Fig. 6b: sampling time S2). The transcript level of $f a b 1$ was, however, only slightly down-regulated at the sampling time S2 compared with that in the presence of copper (Fig. 6c: sampling time S2), indicating that this short period of culture before cellulase induction would contribute to the initiation of the RNAi process toward the target gene. After 6- (Fig. 6c: sampling time S3) and 12-h (Fig. 6c: sampling time S4) induction on Avicel, the abundance of $f a b 1$ mRNA reduced dramatically in the absence of copper, which was in sharp contrast with the no obvious decrease in fab1 mRNA quantity in the presence of copper. Correspondingly, the $\mathrm{P}_{t c u 1}-f a b 1^{\mathrm{KD}}$ strain displayed significantly reduced extracellular FPA and protein accumulation upon induction without copper compared those with copper (Fig. 6d-f).

\section{Discussion}

Trichoderma reesei is capable of secreting a large amount of proteins and represents a major workhorse for production of cellulases and other recombinant proteins as well [46]. Since its first isolation and the discovery for its astonishing potential to produce extracellular cellulases, extensive efforts have been made to further improve the production of T. reesei cellulases and thus to facilitate its industrial application through classical mutagenesis and screening, culminating in the isolation of strain RUT-C30 with a malfunction of the catabolite repressor CRE1 [47]. It is noteworthy that some strains used for the production of cellulases and hemicellulases on the industrial scale are descendants of RUT-C30 [48]. With the advent of fungal gene manipulation techniques, molecular biological strategies including HR-based gene deletion or overexpression were increasingly employed for strain improvement [49]. Such attempts have been best demonstrated by the introduction of $\beta$-glucosidases as well as other accessory proteins into $T$. reesei to act in synergistic way with $T$. reesei cellulases during biomass hydrolysis $[5,48,50]$. It is therefore not surprising that modern commercial cellulase preparations are usually based on genetically modified strains of $T$. reesei possessing rather high $\beta$-glucosidase activity [51]. In the genomic and postgenomic era, comparative genomic studies of $T$. reese $i$ mutant strains resulted in the identification of potentially critical factors in lignocellulosic enzyme production and regulation, which further facilitate the rational design and 

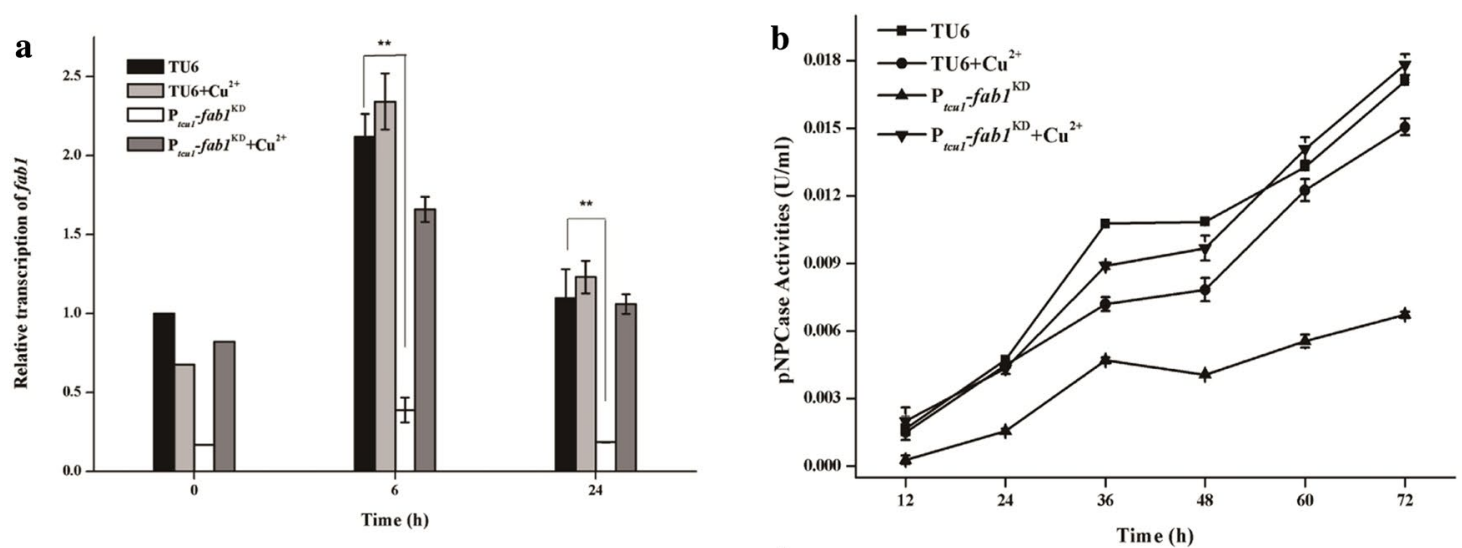

c

d
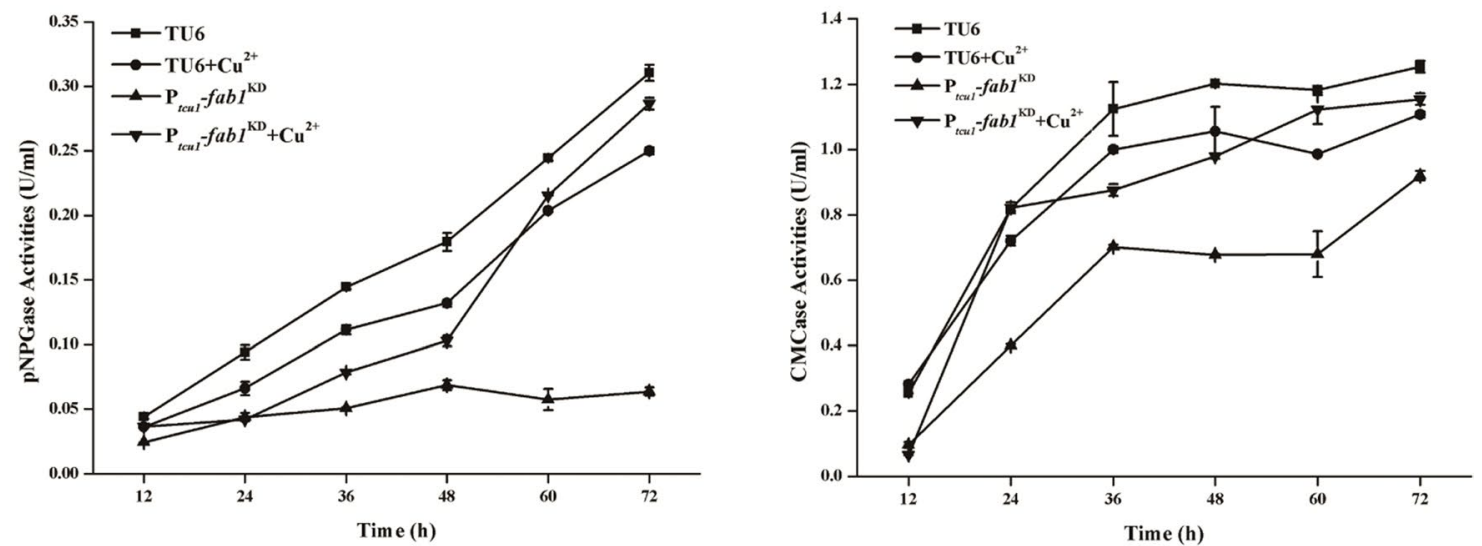

$\mathbf{e}$

TU6

$\mathbf{P}_{t c u 1}-f a b 1^{\mathrm{KD}}$

f

TU6

$\mathbf{P}_{t c u 1}-f a b 1^{\mathrm{KD}}$
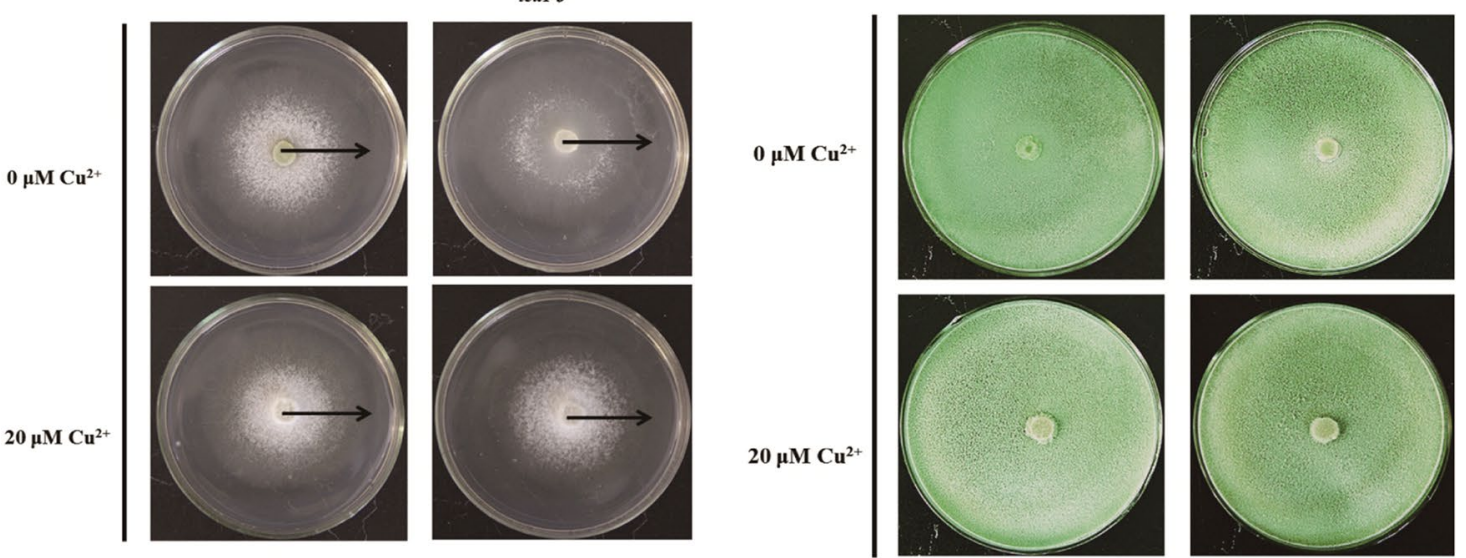

Fig. 5 Knockdown of fab 1 by copper-responsive RNAi-mediated silencing system. The abundance of fab1 mRNAs (a), extracellular pNPC (b) pNPG (c) and CMC (d) hydrolytic activity of the parental and $P_{t c u 1}-f a b 7^{K D}$ strains cultured on $1 \%(\mathrm{~W} / \mathrm{v})$ Avicel supplied with or without copper were determined. Mycelial growth (e) and sporulation (f) of the parental TU6 and $\mathrm{P}_{\mathrm{tcu}}-\mathrm{fab}{ }^{\mathrm{KD}}$ strains on agar plate containing $1 \%$ glucose and malt extract agar plate, respectively, supplied with or without copper were investigated

construction of lignocellulosic enzyme hyper-production strains and the optimization of the enzyme profiles of $T$. reesei by genetic engineering [52]. This, however, requires a more versatile molecular tool box that enables easy manipulation of genes which is a prerequisite for strain engineering.

Although homologous recombination has been the major approach for producing knockout strains in $T$. 

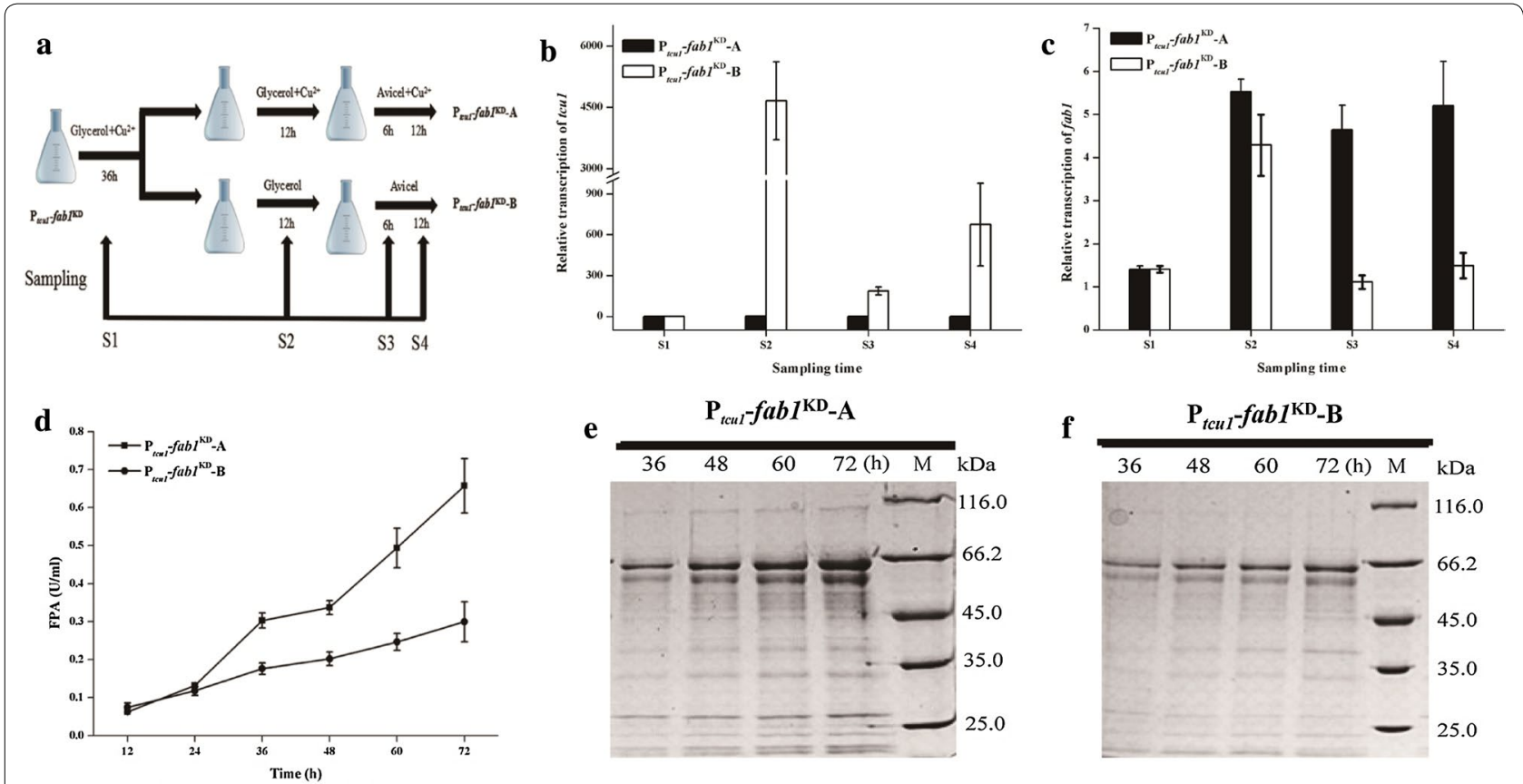

Fig. 6 Redesigned culture strategy to verify the functional role of fab1 in cellulase production. Two culture procedures (a) were designed for functional study of fab1 in T. reesei using the copper-responsive RNAi-mediated silencing system. The abundance of fabl (b) and tcul (c) mRNAs was quantified by qRT-PCR in the appointed sampling times. Filter paper activity was measured when mycelia were transferred into Avicel induction media at indicated time (d). Extracellular fermentation liquor $(20 \mu \mathrm{L})$ of $\mathrm{P}_{\text {tcul }}-\mathrm{fab} 1^{\mathrm{KD}}$ strain cultured on $1 \%$ Avicel supplied with (e) or without (f) copper was analyzed by SDS-PAGE

reesei with varying levels of success, RNAi as a powerful tool in the functional genomic studies in eukaryotes could be employed for partial or condition-specific suppression of gene expression, particularly when gene deletion could be detrimental or even lethal. An ideal inducible RNAi system should be inactive in the un-induced state to prevent undesired gene silencing, and be rapidly induced to be able to repress target gene expression and also be reversible. The ability to manipulate gene expression in this way is thus anticipated to facilitate dissecting the functions of genes that give lethal or complex pleiotropic phenotypes in knockout mutants or stable RNAi transformant. In this study, we successfully knocked down the constitutively expressed pyr4 gene, Avicel inducing xyr 1 and cel7a genes using the developed copper-controlled RNAi system. The RNAi strains displayed the same phenotype as that of deletion strains when copper was absent in the media by down-regulating the target gene expression, but behaved similarly as the parental strains when copper was present in the media. These data thus indicated that the developed responsive RNAi system could on the one hand readily knock down/off the target gene allowing the phenotypic characterization, whereas on the other hand it could mimic the complementation to exclude any unwanted effects resulted from the random integration of the hpRNA cassette by adding copper ions in the media. Compared with previously developed RNAi system with the constitutive or inducible promoter in $T$. reesei $[31,32]$, the present copper-responsive RNAi system does not depend on certain nutrition state and thus is applicable in any culture media. Importantly, the conditional silencing of the target gene allows the possibility to exclude any effect exerted by the differential growth between the RNAi strain and the control strain by specifically designed culture strategies. It should be pointed out that it would be convenient if the copper-controlled RNAi system could be turned on by directly adding specific copper chelators to the culture. Although our previous study demonstrated that trace amount of copper ions in the culture $(<200 \mathrm{nM})$ had hardly any effect on the expression of the $t c u 1$ gene, the copper chelator bathocuproinedisulfonic acid (BCS) could only partially relieved the $t c u 1$ repression and may therefore not be ideal for this system [28]. Nevertheless, we found that directly adding the copper to the culture can shut down the expression of hpRNA, simply washing the culture before transfer to 
a fresh medium without copper is an effective way to turn on hpRNA expression.

Taking advantage of the controllability of our copperresponsive RNAi-mediated gene silencing system, we investigated the function of $f a b 1$ gene for cellulase production, whose deletion was proven to be intractable with repetitive attempts. Our results showed that the knocking down of $f a b 1$ significantly reduced the cellulase production, whereas transcriptional analysis revealed that cellulase gene transcription was not affected. Thus, we speculated that RNAi-mediated down-regulation of the $f a b 1$ gene may interfere with other aspects of cellulase gene expression including protein sorting and transport rather than transcription. Considering that RNAi-mediated down-regulation of the $f a b 1$ gene showed no visible phenotypic deficiency regarding mycelial growth and sporulation, the failure to delete $f a b 1$ by homologous recombination was probably not due to the growth defect of the resultant mutant strain. Nevertheless, possibility cannot be ruled out that a low level of $f a b 1$ transcripts due to the incomplete silencing of $f a b 1$ was sufficient for the growth of the $\mathrm{P}_{t c u 1}-f a b 1^{\mathrm{KD}}$ strain while the complete knockout of $f a b 1$ was lethal. The $f a b 1$ gene may thus play differential roles in T. reesei and the exact mechanism of $f a b 1$ on cellulose production requires further studies.

Previously, we developed a promoter replacement system, in which $\mathrm{P}_{t c u 1}$ promoter was used to substitute the target endogenous promoter in situ [53]. Including cooper in the media results in the repression of target gene transcription while overexpression of target genes is achieved by excluding the copper in the media. The usefulness of this system has been illustrated by investigating the function of two subunits (Gcn5 and Ada2) of the putative Spt-Ada-Gcn5 acetyltransferase complex, whose knockouts were proven to cause severely defect in mycelia growth and spore formation [53, 54]. However, we noticed that the repression of some genes transcribed at a low level by $\mathrm{P}_{t c u 1}$ promoter replacement system was not successful (data not shown), probably due to the slight leakage of the $\mathrm{P}_{t c u l}$ promoter. On the other hand, in the absence of copper, the high-level expression of the target genes in the promoter-replaced strain would sometimes complicate the phenotypic analysis. In the present study, we further developed a $\mathrm{P}_{t c u} 1^{- \text {driven }}$ RNAi-mediated silencing system to solve this issue. Thus, combining the $\mathrm{P}_{\text {tcul }}$ promoter replacement system and the present $\mathrm{P}_{\text {tcul }}$-driven RNAi-mediated silencing system provides us the effective complementary tool set for the overexpression and knocking down of most genes in $T$. reesei for functional genomic studies.

\section{Conclusion}

In this study, we developed an RNAi-mediated silencing system driven by the $\mathrm{P}_{t c u 1}$ promoter which is highly responsive to the copper ions. The developed RNAi system could readily knock down/off the target gene in the absence of copper allowing the phenotypical characterization and could mimic the complementation of the deficient strain simply by including copper in the media to exclude the unwanted effect that may result from the random integration of the hpRNA cassette. The copperresponsive RNAi-mediated silencing system is applicable on different nutritional states and represents a powerful tool for characterizing target gene functions in T. reesei.

\section{Additional file}

Additional file 1. Figures and Table.

\section{Abbreviations}

$P_{\text {tcui }}$ : tcu1 promoter; RNAi: RNA interference; HR: homologous recombination; NHEJ: non-homologous end joining; siRNA: small interfering RNA; hpRNA: hairpin RNA; FPA: filter paper activities; CMC: carboxymethylcellulose sodium salt; $\mathrm{pNPC}$ : -nitrophenyl- $\beta$-D-cellobioside; $\mathrm{PNPG}$ : $p$-nitrophenyl- $\beta$-Dglucopyranoside; PtdIns(3)P: phosphatidylinositol 3-phosphate; Ptdlns $(3,5) \mathrm{P}_{2}$ phosphatidylinositol 3,5-bisphosphate; BCS: bathocuproinedisulfonic acid.

\section{Authors' contributions}

LW, XFM and WFL designed the experiments, and LW and FLZ performed the experiments. LW, FLZ, WXZ, YHZ and GJC analyzed the results. LW, XFM, and WFL wrote the manuscript. All authors read and approved the final manuscript.

\section{Competing interests}

The authors declare that they have no competing interests.

Availability of data and materials Not applicable.

Consent for publication

Not applicable.

Ethics approval and consent to participate Not applicable.

\section{Funding}

This work is supported by Grants from the National Natural Science Foundation of China (31670040, 31470162, and 31770047), National Key Technology Support Program (2015BAD15B05) and Key Research and Development Support Program of Shandong Province (2016GGH3103).

\section{Publisher's Note}

Springer Nature remains neutral with regard to jurisdictional claims in published maps and institutional affiliations.

Received: 29 November 2017 Accepted: 1 February 2018

Published online: 09 February 2018 


\section{References}

1. Bomble YJ, Lin CY, Amore A, Wei H, Holwerda EK, Ciesielski PN, Donohoe BS, Decker SR, Lynd LR, Himmel ME. Lignocellulose deconstruction in the biosphere. Curr Opin Chem Biol. 2017;41:61-70.

2. McCann MC, Carpita NC. Biomass recalcitrance: a multi-scale, multi-factor, and conversion-specific property. J Exp Bot. 2015;66:4109-18.

3. Ding SY, Liu YS, Zeng YN, Himmel ME, Baker JO, Bayer EA. How does plant cell wall nanoscale architecture correlate with enzymatic digestibility? Science. 2012;338:1055-60.

4. Sharma RK, Arora DS. Fungal degradation of lignocellulosic residues: an aspect of improved nutritive quality. Crit Rev Microbiol. 2015;41:52-60.

5. Harris PV, Welner D, McFarland KC, Re E, Navarro Poulsen JC, Brown K, Salbo R, Ding H, Vlasenko E, Merino S, et al. Stimulation of lignocellulosic biomass hydrolysis by proteins of glycoside hydrolase family 61: structure and function of a large, enigmatic family. Biochemistry. 2010;49:3305-16.

6. Hu JG, Arantes V, Pribowo A, Gourlay K, Saddler JN. Substrate factors that influence the synergistic interaction of AA9 and cellulases during the enzymatic hydrolysis of biomass. Energ Environ Sci. 2014:7:2308-15.

7. Andberg M, Penttila M, Saloheimo M. Swollenin from Trichoderma reesei exhibits hydrolytic activity against cellulosic substrates with features of both endoglucanases and cellobiohydrolases. Bioresour Technol. 2015;181:105-13.

8. Kubicek CP, Kubicek EM. Enzymatic deconstruction of plant biomass by fungal enzymes. Curr Opin Chem Biol. 2016;35:51-7.

9. Gupta VK, Kubicek CP, Berrin JG, Wilson DW, Couturier M, Berlin A, Filho EXF, Ezeji T. Fungal enzymes for bio-products from sustainable and waste biomass. Trends Biochem Sci. 2016:41:633-45.

10. Kubicek CP, Mikus M, Schuster A, Schmoll M, Seiboth B. Metabolic engineering strategies for the improvement of cellulase production by Hypocrea jecorina. Biotechnol Biofuels. 2009;2:19.

11. Bisch of RH, Ramoni J, Seiboth B. Cellulases and beyond: the first 70 years of the enzyme producer Trichoderma reesei. Microb Cell Fact. 2016;15:106.

12. Druzhinina IS, Kubicek CP. Familiar stranger: ecological genomics of the model saprotroph and industrial enzyme producer Trichoderma reesei breaks the stereotypes. Adv Appl Microbiol. 2016;95:69-147.

13. Cherry JR, Fidantsef AL. Directed evolution of industrial enzymes: an update. Curr Opin Biotechnol. 2003;14:438-43.

14. Stappler E, Dattenbock C, Tisch D, Schmoll M. Analysis of light- and carbon-specific transcriptomes implicates a class of G-protein-coupled receptors in cellulose sensing. mSphere. 2017;2:e00089-17.

15. Tisch D, Schmoll M. Targets of light signalling in Trichoderma reesei. BMC Genom. 2013:14:657.

16. Wang M, Zhao Q, Yang J, Jiang B, Wang F, Liu K, Fang X. A mitogenactivated protein kinase Tmk3 participates in high osmolarity resistance, cell wall integrity maintenance and cellulase production regulation in Trichoderma reesei. PLOS ONE. 2013:8:e72189.

17. Mello-de-Sousa TM, Rassinger A, Derntl C, Pocas-Fonseca MJ, Mach $\mathrm{RL}$, Mach-Aigner AR. The relation between promoter chromatin status, Xyr1 and cellulase expression in Trichoderma reesei. Curr Genomics. 2016;17:145-52.

18. Cao Y, Zheng F, Wang L, Zhao G, Chen G, Zhang W, Liu W. Rce1, a novel transcriptional repressor, regulates cellulase gene expression by antagonizing the transactivator Xyr 1 in Trichoderma reesei. Mol Microbiol. 2017;105:65-83.

19. Nogueira KM, Costa Mdo N, de Paula RG, Mendonca-Natividade FC, RicciAzevedo R, Silva RN. Evidence of CAMP involvement in cellobiohydrolase expression and secretion by Trichoderma reesei in presence of the inducer sophorose. BMC Microbiol. 2015;15:195.

20. Martinez D, Berka RM, Henrissat B, Saloheimo M, Arvas M, Baker SE, Chapman J, Chertkov O, Coutinho PM, Cullen D, et al. Genome sequencing and analysis of the biomass-degrading fungus Trichoderma reesei (syn Hypocrea jecorina). Nat Biotechnol. 2008;26:553-60.

21. Penttila M, Nevalainen $H$, Ratto M, Salminen E, Knowles J. A versatile transformation system for the cellulolytic filamentous fungus Trichoderma reesei. Gene. 1987;61:155-64.

22. Hartl L, Seiboth B. Sequential gene deletions in Hypocrea jecorina using a single blaster cassette. Curr Genets. 2005;48:204-11.

23. Guangtao Z, Hartl L, Schuster A, Polak S, Schmoll M, Wang T, Seidl V, Seiboth B. Gene targeting in a nonhomologous end joining deficient Hypocrea jecorina. J Biotechnol. 2009;139:146-51
24. Steiger MG, Vitikainen M, Uskonen P, Brunner K, Adam G, Pakula T, Penttila M, Saloheimo M, Mach RL, Mach-Aigner AR. Transformation system for Hypocrea jecorina (Trichoderma reesei) that favors homologous integration and employs reusable bidirectionally selectable markers. Appl Environ Microbiol. 2011:77:114-21.

25. Chum PY, Schmidt G, Saloheimo M, Landowski CP. Transient silencing of DNA repair genes improves targeted gene integration in the filamentous fungus Trichoderma reesei. Appl Environ Microbiol. 2017;83:e00535-17.

26. Bischof RH, Horejs J, Metz B, Gamauf C, Kubicek CP, Seiboth B. L-Methionine repressible promoters for tuneable gene expression in Trichoderma reesei. Microb Cell Fact. 2015;14:120.

27. Lv X, Zheng F, Li C, Zhang W, Chen G, Liu W. Characterization of a copper responsive promoter and its mediated overexpression of the xylanase regulator 1 results in an induction-independent production of cellulases in Trichoderma reesei. Biotechnol Biofuels. 2015;8:67.

28. Chang SS, Zhang Z, Liu Y. RNA interference pathways in fungi: mechanisms and functions. Annu Rev Microbiol. 2012;66:305-23.

29. Czarnecki O, Bryan AC, Jawdy SS, Yang X, Cheng ZM, Chen JG, Tuskan GA. Simultaneous knockdown of six non-family genes using a single synthetic RNAi fragment in Arabidopsis thaliana. Plant Methods. 2016:12:16.

30. Nami S, Baradaran B, Mansoori B, Kordbacheh P, Rezaie S, Falahati M, Mohamed Khosroshahi L, Safara M, Zaini F. The utilization of RNA silencing technology to mitigate the voriconazole resistance of Aspergillus Flavus, lipofectamine-based delivery. Adv Pharm Bull. 2017;7:53-9.

31. Qin LN, Cai FR, Dong XR, Huang ZB, Tao Y, Huang JZ, Dong ZY. Improved production of heterologous lipase in Trichoderma reesei by RNAi mediated gene silencing of an endogenic highly expressed gene. Bioresour Technol. 2012;109:116-22.

32. Schmoll M, Schuster A, Silva Rdo N, Kubicek CP. The Ga protein GNA3 of Hypocrea jecorina (Anamorph Trichoderma reesei) regulates cellulase gene expression in the presence of light. Eukaryot Cell. 2009:8:410-20.

33. Xu JT, Zhao GL, Kou YB, Zhang WX, Zhou QX, Chen GJ, Liu WF. Intracellular $\beta$-glucosidases CEL1a and CEL1b are essential for cellulase induction on lactose in Trichoderma reesei. Eukaryot Cell. 2014;13:1001-13.

34. Zhou Q, Xu J, Kou Y, Lv X, Zhang X, Zhao G, Zhang W, Chen G, Liu W. Differential involvement of $\beta$-glucosidases from Hypocrea jecorina in rapid induction of cellulase genes by cellulose and cellobiose. Eukaryot Cell. 2012:11:1371-81

35. Smith JL, Bayliss FT, Ward M. Sequence of the cloned pyr4 gene of Trichoderma reesei and its use as a homologous selectable marker for transformation. Curr Genet. 1991;19:27-33.

36. Mach-Aigner AR, Pucher ME, Steiger MG, Bauer GE, Preis SJ, Mach RL. Transcriptional regulation of $x y r 1$, encoding the main regulator of the xylanolytic and cellulolytic enzyme system in Hypocrea jecorina. Appl Environ Microbiol. 2008;74:6554-62.

37. Stricker AR, Grosstessner-Hain K, Wurleitner E, Mach RL. Xyr1 (xylanase regulator 1) regulates both the hydrolytic enzyme system and D-xylose metabolism in Hypocrea jecorina. Eukaryot Cell. 2006;5:2128-37.

38. Stricker AR, Steiger MG, Mach RL. Xyr 1 receives the lactose induction signal and regulates lactose metabolism in Hypocrea jecorina. FEBS Lett. 2007:581:3915-20.

39. Furukawa T, Shida Y, Kitagami N, Mori K, Kato M, Kobayashi T, Okada H, Ogasawara W, Morikawa Y. Identification of specific binding sites for XYR1, a transcriptional activator of cellulolytic and xylanolytic genes in Trichoderma reesei. Fungal Genet Biol. 2009:46:564-74.

40. Silva-Rocha R, Castro Ldos S, Antonieto AC, Guazzaroni ME, Persinoti GF, Silva RN. Deciphering the cis-regulatory elements for XYR1 and CRE1 regulators in Trichoderma reesei. PLoS ONE. 2014;9:e99366.

41. Lang MJ, Strunk BS, Azad N, Petersen JL, Weisman LS. An intramolecular interaction within the lipid kinase Fab1 regulates cellular phosphatidylinositol 3,5-bisphosphate lipid levels. Mol Biol Cell. 2017;28:858-64.

42. McCartney AJ, Zhang Y, Weisman LS. Phosphatidylinositol 3,5-bisphosphate: low abundance, high significance. BioEssays. 2014;36:52-64.

43. Gary JD, Wurmser AE, Bonangelino CJ, Weisman LS, Emr SD. Fab1p is essential for Ptdlns(3)P 5-kinase activity and the maintenance of vacuolar size and membrane homeostasis. J Cell Biol. 1998;143:65-79.

44. Dong XP, Shen D, Wang X, Dawson T, Li X, Zhang Q, Cheng X, Zhang Y, Weisman LS, Delling M, Xu H. PI(3,5)P(2) controls membrane trafficking by direct activation of mucolipin $\mathrm{Ca}^{(2+)}$ release channels in the endolysosome. Nat Commun. 2010;1:38. 
45. Han BK, Emr SD. Phosphoinositide [PI(3,5)P2] lipid-dependent regulation of the general transcriptional regulator Tup1. Genes Dev. 2011;25:984-95.

46. Druzhinina IS, Kubicek CP. Genetic engineering of Trichoderma reesei cellulases and their production. Microb Biotechnol. 2017;10:1485-99.

47. Peterson R, Nevalainen H. Trichoderma reesei RUT-C30-30 years of strain improvement. Microbiology. 2012;158:58-68.

48. Li CC, Lin FM, Zhou L, Qin L, Li BZ, Zhou ZH, Jin MJ, Chen Z. Cellulase hyper-production by Trichoderma reesei mutant SEU-7 on lactose. Biotechnol Biofuels. 2017;10:228.

49. Steiger MG. Molecular tools in Trichoderma genetic studies. In: Mukherjee PK, Horwitz BA, Singh US, Mukherjee M, Schmoll M, editors. Trichoderma: biology and applications. Boston: CABl; 2013. p. 128-43.

50. Gao J, Qian YC, Wang YF, Qu YB, Zhong YH. Production of the versatile cellulase for cellulose bioconversion and cellulase inducer synthesis by genetic improvement of Trichoderma reesei. Biotechnol Biofuels. 2017:10:272.

51. Merino ST, Cherry J. Progress and challenges in enzyme development for biomass utilization. Adv Biochem Eng Biotechnol. 2007;108:95-120.

52. Gupta VK, Steindorff AS, de Paula RG, Silva-Rocha R, Mach-Aigner AR, Mach RL, Silva RN. The post-genomic Era of Trichoderma reesei: what's next? Trends Biotechnol. 2016;34:970-82.

53. Zheng F, Cao Y, Lv X, Wang L, Li C, Zhang W, Chen G, Liu W. A copperresponsive promoter replacement system to investigate gene functions in Trichoderma reesei: a case study in characterizing SAGA genes. Appl Microbiol Biotechnol. 2017;101:2067-78.

54. Xin Q, Gong Y, Lv X, Chen G, Liu W. Trichoderma reesei histone acetyltransferase $G c n 5$ regulates fungal growth, conidiation, and cellulase gene expression. Curr Microbiol. 2013;67:580-9.

\section{Submit your next manuscript to BioMed Central and we will help you at every step:}

- We accept pre-submission inquiries

- Our selector tool helps you to find the most relevant journal

- We provide round the clock customer support

- Convenient online submission

- Thorough peer review

- Inclusion in PubMed and all major indexing services

- Maximum visibility for your research

Submit your manuscript at www.biomedcentral com/submit 